\title{
Forest cover selection and activity of cow moose in summer
}

\author{
Mike W. DEMARCHI ${ }^{1}$ and Fred L. BUNNELL ${ }^{2}$
}

\begin{abstract}
Mike W. Demarchi and Fred L. Bunnell 1995. Forest cover selection and activity of cow moose in summer. Acta Theriologica 40: 23-36.

Although thermal cover receives attention from managers, variations in data regarding its use by ungulates hinders development of effective cover guidelines. We examined patterns of habitat selection and activity of radio-collared cow moose Alces alces Linnaeus, 1758 to determine if these 2 parameters were influenced by ambient thermal environment. Cow moose used sites with relatively denser forest canopies when conditions of heat stress existed in open areas. Use of open areas did not change with ambient temperature; some sites classed as open on forest cover maps, however, had willow canopies capable of providing thermal cover. An increase in the use of open sites from 11.00 to $24.00 \mathrm{hr}$ corresponded to a simultaneous decrease in the likelihood of thermal stress in such areas; predator-avoidance was deemed unlikely to explain observed behaviour. Moose decreased activity and distance traveled between successive locations during hot periods. Summer thermal cover is a selected, manageable component of moose habitat in southern British Columbia.
\end{abstract}

Center for Applied Conservation Biology, University of British Columbia, 193-2357 Main Mall, Vancouver, BC, Canada V6T 1Z4

Key words: Alces alces, habitat selection, heat stress, thermal cover, radio telemetry

\section{Introduction}

When ambient temperatures exceed an animal's upper critical temperature it experiences additional energy and time costs associated with heat dissipation (Bligh and Johnson 1973). There are compelling reasons to expect animals experiencing these costs to seek environments that reduce the costs. Evidence for large ungulates can be summarized simply: large heat loads impose high thermoregulatory costs, which in moose can reduce summer weight gains despite abundant forage (Reneker and Hudson 1986). In areas of harsh winters, decreased summer weight gains can increase winter and spring mortality (Mautz 1978). By deduction, summer thermal cover could affect moose survival. Despite the potential for thermal cover to modify ungulate behavior, productivity, and survival, published observations of responses vary.

\footnotetext{
1 Present address: 101-12571 Cambie Road Richmond, BC, Canada V6V 2A9

${ }^{2}$ Corresponding author
} 
Several authors have concluded that areas providing summer thermal cover are preferred by elk (Young and Robinette 1939, Lyon 1979, Pederson et al. 1980) and moose (Schwab 1986, Ackerman 1987, Renecker 1987). Other authors have found high densities of large ungulates in areas with little or no summer thermal cover (Peek et al. 1982, Merrill 1991). There are at least 4 reasons why observed use of thermal cover is seemingly inconsistent. First, animals integrate responses to many elements of their environment (Peek et al. 1982). Second, in that integration process animals may be 'satisficing' rather than optimizing their assumed goals of comfort and survival (Bunnell and Gillingham 1985, Bunnell et al. 1987). Third, thermal inertia in large ungulates (Peters 1983) may invalidate simultaneous comparisons of habitat use vs thermal environment because the animal's response to heat load is delayed. Fourth, the actual meliorative effects of particular cover types on the processes generating potential heat load are more often assumed than measured (Pederson 1975, Nyberg and Janz 1990).

Although there are good reasons for the variable responses of ungulates to thermal cover, they remain troublesome because guidelines for managing thermal cover have been offered (e.g. Black et al. 1976, Thomas et al. 1979, Leckenby and Adams 1981, Dealy 1985, Ritcey et al. 1988, Nyberg and Janz 1990). Variable ungulate responses reduce credibility of requests to modify habitat specifically for thermal cover. We attempted to evade most reasons for variable responses by clearly defining summer thermal cover for moose in terms of canopy structure (Demarchi and Bunnell 1993) and allowing for thermal inertia in our evaluation. Summer thermal cover includes those forest canopies that reduce the 'operative temperature' (Te; Campbell 1977) experienced by a moose to near or below upper critical temperature under prevailing meteorological conditions. That definition allows us to observe responses of moose relative to habitats that should be preferred when thermal stress is operating. We predicted responses of moose to heat loads. Specifically, moose should be located in habitats reducing heat load when the potential for heat stress occurs or after some delay encouraged by thermal inertia, and moose should be least active during the warmest hours of the day or after a delay.

\section{Study area}

The 15,000 ha study site was located in the Montane Spruce biogeoclimatic zone of the Southern Thompson Upland Ecosection, Southern Interior Ecoprovince $\left(50^{\circ} \mathrm{N}, 120^{\circ} \mathrm{W}\right.$; Demarchi 1990 , Lloyd et al. 1990). Elevation ranged from $1400-1500 \mathrm{~m}$. Through past fires, most forested sites were occupied by mature lodgepole pine Pinus contorta (Lloyd et al. 1990). Scattered veteran and understory trees were hybrid white spruce Picea glauca $\times$ englmannii and subalpine fir Abies lasiocarpa. The terrain was relatively level and much of the forested area was highly interspersed with riparian communities. Riparian sites were dominated by sedge Carex spp., willow Salix spp., and glandular bog birch Betula glandulosa. Forestry is the major land use in the area. 


\section{Methods}

\section{Weather station}

A weather station was erected 17 June 1990 in a 7 ha meadow dominated by sedges and glandular bog birch $<1.5 \mathrm{~m}$ in height. A Campbell Scientific CR21 data logger recorded hourly averages of readings taken at $60 \mathrm{sec}$ intervals from a leveled Li-Cor pyranometer (cosine corrected, model LI200S), Met-One anemometer (model 014A; minimum detectable wind speed $=0.4 \mathrm{~m} \times \mathrm{sec}^{-1}$ ), and temperature probe (Campbell Scientific model 207). The data logger was enclosed in a rain-tight fiberglass case covered by a metal radiation shield. The pyranometer and anemometer were mounted on a mast at $2.5 \mathrm{~m}$ and $2.9 \mathrm{~m}$, respectively. The temperature probe was placed inside a Stevenson screen at a height of $2.0 \mathrm{~m}$.

\section{Operative temperatures}

To describe thermal environments experienced by a moose, a simulation model based on Te was used (Parker and Gillingham 1990, Demarchi and Bunnell 1993). By visually comparing canopy density on aerial photos with known standards, forestry cartographers assign crown closure classes (CCC) to forest stands. In British Columbia, CCC values from 0 to 10 correspond to non-overlapping intervals of percent crown closure on forest cover maps (Table 1). Hemispherical photo data were used to estimate CCC-specific subcanopy radiation regimes and subcanopy operative temperatures (Demarchi and Bunnell 1993). We used a tripod-mounted Nikon SE camera and a $180^{\circ}$ fish-eye lens $(8 \mathrm{~mm}$ focal length), to sample a minimum of 3 different forest stands corresponding to each of the British Columbia Ministry of Forests' CCC 3 to 8 inclusive. Dominant and codominant trees were at least $10 \mathrm{~m}$ tall. Photo sites were a minimum of 3 tree heights (i.e. $>30 \mathrm{~m}$ in this study) from the nearest different CCC or cover type. All photos were taken under conditions of no wind and overcast skies. Light was measured with a Sekonic (model L-398) light meter calibrated with a Li-Cor photometer (model Li185). Photos were taken at a 'shutter priority' speed of $0.5 \mathrm{sec}$ with Kodalith Hi-Contrast, black and white, ASA 6 film. One photo was taken at each of 3,4 , and 5 f-stops above the value indicated by the light meter. Underexposure (according to the light meter) maximized the contrast between the trees and sky.

Using a Logitech (model Scanman Plus) digital scanner, 3 photos from each of 3 sites were scanned. The photos consisted of 1 that was overexposed by 1

Table 1. Crown closure classes and their corresponding percent limits of coverage as used by the British Columbia Ministry of Forests. This scheme does not account for gaps within individual tree crowns.

\begin{tabular}{cc}
\hline $\begin{array}{l}\text { Crown Closure } \\
\text { Class (CCC) }\end{array}$ & Limits $(\%)$ \\
\hline 0 & $0-5$ \\
1 & $6-15$ \\
2 & $16-25$ \\
3 & $26-35$ \\
4 & $36-45$ \\
5 & $46-55$ \\
6 & $56-65$ \\
7 & $66-75$ \\
8 & $76-85$ \\
9 & $86-95$ \\
10 & $96-100$ \\
\hline
\end{tabular}
f-stop, 1 that was correctly exposed, and 1 that was underexposed by $1 \mathrm{f}$-stop. Correct exposure maximized plant/sky contrast while retaining foliar resolution. Using software developed by Chen et al. (1991), the digital scans were subjected to algorithms which derived effective leaf area index (Le) ${ }^{1}$ (Chen et al. 1991) and sky view factor (SVF) (Norman and Campbell 1989, Chen et al. 1991) through the integration of gap fractions. Respective

${ }^{1}$ Leaf area index is one half of the total surface area of leaves per unit forest floor area. Effective leaf area index is the product of leaf area index and a clumping index $(\Omega$ ) (for random leaf spatial distribution, $\Omega=1$; Black et al. 1991). 
differences between the SVF and Le values of the underexposed and correctly exposed, and the overexposed and correctly exposed photos were averaged to establish Le and SVF correction factors. From each of the remaining sets of photos, the photo nearest the correct exposure (i.e. $\leq 1 \mathrm{f}$-stop) was scanned and subjected to the same computer analysis. If the best photo of a set appeared underexposed or overexposed, the Le and SVF correction factors were added or subtracted to obtain corrected Le and SVF values. Ten of 35 photos required correction.

Seven sites with no CCC value defined on the forest cover map were also sampled. These sites ranged from beneath willow canopies to edge habitats. Theoretically, a site with no cover $(\mathrm{CCC}=0)$ has respective SVF and Le values of 1 and 0 ; that is, $100 \%$ of the sky is visible and there are no tree leaves above the ground. If the SVF and Le values of these 'undefined' sites were closer to the theoretical values of a $\mathrm{CCC}=0$ site than the observed values of $\mathrm{CCC}=3$ sites, they were assigned to $\mathrm{CCC}=1$. No $\mathrm{CCC}=1$ sites were mapped in the study area; the purpose of this interpolation was to assess the validity of forcing a regression line through the theoretical point $\mathrm{CCC}=0, \mathrm{SVF}=1$. Regression equations were fitted to plots of the average SVF and Le values against CCC. An additional equation was obtained by regressing SVF against Le. Where appropriate, regression lines were forced through the theoretical coordinate pairs (i.e. $\mathrm{CCC}=0, \mathrm{SVF}=1 ; \mathrm{CCC}=0, \mathrm{Le}=0 ; \mathrm{Le}=0$, $\mathrm{SVF}=1$ ). From these regressions, CCC-specific SVF and LE values were used to partially determine sub-canopy radiation regimes (Chen et al. 1991) in the operative temperature model.

Renecker and Hudson (1986) reported that the upper critical air temperature (UCTam) for moose in summer was between $14^{\circ} \mathrm{C}$ and $20^{\circ} \mathrm{C}$. Demarchi and Bunnell (1993) regressed $\mathrm{Te}$ in open areas ( $\mathrm{Te}_{\text {open }}$ ) against air temperature (Tam) data for hours when moose were located and found that Tam of $14^{\circ} \mathrm{C}$ and $20^{\circ} \mathrm{C}$ corresponded to $\mathrm{Te}_{\text {open }}$ values of $13.0^{\circ} \mathrm{C}$ and $29.5^{\circ} \mathrm{C}$, respectively $\left(\mathrm{Te}=0.03 \times \mathrm{Tam}^{2.30}\right.$, $\mathrm{I}^{2}=0.73, \mathrm{SE}=1.6, n=252$ ). Here we conservatively define hot conditions ( $\mathrm{Te}$ open: hot) to be when $\mathrm{Te}$ open was $>29.5^{\circ} \mathrm{C}$, and cool conditions ( $\mathrm{Te} \mathrm{e}_{\text {open }}$ : cool) to be when $\mathrm{Te}_{\text {open }}$ was $<13.0^{\circ} \mathrm{C}$. 'Intermediate' conditions existed between these limits. Renecker and Hudson (1986) conducted their observations under uncontrolled conditions with respect to solar radiation and wind. Had their observations been made in a controlled environment, Te values of $14^{\circ} \mathrm{C}$ and $20^{\circ} \mathrm{C}$ could have been used as the thermal limits in this study. Day or 'light' conditions existed when the mean hourly solar flux density (MHSFD) was $\geq 50 \mathrm{~W} \times \mathrm{m}^{-2}$. Night or 'dark' conditions existed when MHSFD was $<50 \mathrm{~W} \times \mathrm{m}^{-2}$.

\section{Radio telemetry}

Four adult cow moose were monitored. Because approaching a moose may influence its choice of habitat, all telemetry was conducted from roads. Logging, highway construction, and recreational activities occurred during the study and we believed that moose were habituated to the sound of vehicles. Moose locations were sampled at minimum intervals of $1 \mathrm{hr}$. If $>1$ animal was being monitored on the same day, interlocation intervals approached $2 \mathrm{hr}$. A typical sampling period spanned $13 \mathrm{hr}$. Most location and activity samples were taken between 11.00 and 24.00 (PDT) to help partition the effects of heat and light on habitat selection and activity.

Moose were not fitted with activity collars. Van Ballenberghe and Miquelle (1990) suggest a modulating signal is a reliable indicator of collar, therefore moose, movement. If $>1$ of the location signals was modulating for the few seconds while each location bearing was sampled, that location was recorded as 'active'. After moose had moved to other locations within their summer home ranges, the general area of telemetered locations was investigated to infer the potential value of each site for foraging. Road access permitted all locations to be made within $800 \mathrm{~m}$ from a road. The study period did not overlap with any hunting seasons. Moose were triangulated using a Lotec receiver, a hand-held Yagi-H antenna, headphones, and a Silva (model Ranger) compass. Compass bearings to each signal were taken from $\geq 3$ sites for each attempted location (e.g. Springer 1979). Information recorded for each location included (1) animal code; (2) date, time at commencement of location, time at completion of location; (3) site-specific compass bearings; and (4) modulating/non-modulating signal. 


\section{Analysis of telemetry data}

Compass bearings were plotted on a 1:15,000 forest cover map. The universal transmercator (UTM) coordinates to the nearest $25 \mathrm{~m}$ were recorded for the center of the polygon formed by the intersection of $\geq 3$ bearings. Telemetry locations were rejected if they met at least 1 of 2 criteria: (1) 3 bearings did not intersect, or (2) the polygon bounded by the bearings contained $>1$ cover-type and had $\geq 1$ side longer than $300 \mathrm{~m}$. Tests of location were conditional (e.g. moose should seek denser canopy under warmer conditions) and do not assume independence among locations (Kremsater and Bunnell 1992).

The average precision of the telemetry system was determined using a $95 \%$ error arc of $\pm 4^{\circ}$. A random sample of 20 moose locations was chosen. The average length of the longest side of each error polygon (Springer 1979) was $150 \mathrm{~m}$. This value was used as the diameter of a circular overlay centered on moose-location UTM coordinates. Analysis of a digitized forest cover map was conducted using the geographic information system TERRASOFT. TERRASOFT was used to quantify the study area by forest crown cover, and to obtain information regarding patterns of habitat use by moose from telemetry overlays.

The Kolmogorov-Smirnov (K-S) 2-sample test compared distributions of the area sums of each CCC $800 \mathrm{~m}$ from a road and the area sums of each CCC on the forest cover map covering the study area. The K-S 2-sample test also compared distributions of the sums of each CCC within telemetry overlays and the sums of each CCC $800 \mathrm{~m}$ from a road. To determine hourly habitat selection in response to temperature, habitat within each overlay was partitioned by CCC and temperature class (cool, intermediate, hot) for $\mathrm{Te}_{\text {open }}$ at the time the location was taken. The resulting distributions were tested in pairs with the K-S 2-sample test. Use of each CCC between pairs of temperature classes was compared with a binomial test of proportions (Zar 1984).

The small surface area to body volume ratio of large animals such as moose results in a reduced rate of heat transfer between animal and environment. The potential effect on cover selection of a delayed response to a hot environment due to thermal inertia was investigated by examining the selection pattern of CCC's across a 13-hr period. As shown by Vales and Bunnell (1988) and Demarchi and Bunnell (1993), the thermal regime beneath a forest canopy is strongly related to canopy closure. Demarchi and Bunnell (1993), however, showed that 2 techniques for quantifying sub-canopy thermal environments reveal that the marginal increase in thermal cover value diminishes rapidly beyond $\mathrm{CCC}=3$. For this reason, and the fact that so few locations were made in CCC $=1-3$ inclusive, we condensed CCC into 2 cover groups: CCC $=0$ and CCC $\geq 4$ for several analyses. When telemetry overlays contained both cover groups, that which represented the greater area was used. Trends in CCC use over time were tested using Pearson correlations. The effect of constant thermal environments (cool, intermediate, and hot) on successive (i.e. $<120 \mathrm{~min}$ apart) locations was tested by examining the patterns of movement between cover-types. For example, if a moose was located under cover at time $=t$, temperature $=$ hot and under cover at time $=t+1$, temperature $=$ hot, that was recorded as 'cover - cover, hot'. Using a test of independent proportions (Hicks 1982), the examination of successive cover choices under specific temperature conditions tested for non-random patterns of habitat selection as a function of the thermal environment.

Using UTM coordinates, the distance between successive moose locations was divided by the time between those locations to yield a mean straight line velocity (MSLV). Ignoring telemetry error, interlocation distance represented a minimum value and likely underestimated actual mean velocity.

\section{Results and discussion}

\section{Habitat analysis}

The proportions of the total study area represented by each CCC did not differ significantly from the CCC proportions inside an $800 \mathrm{~m}$ strip adjacent to each side 
of the roads $(p>0.05)$. The similarity between the 2 distributions indicated that potential moose activity and location sampling were not biased to a habitat mix that was atypical of the study area.

\section{Habitat use under different heat loads}

Moose locations $(n=252)$ were recorded across a range of ambient radiative and temperature conditions. The relation between Te and Tam for CCC $=0$ s.tes (i.e. $\mathrm{Te}=0.03 \times \mathrm{Tam}^{2.30}$ ) indicated that for the weather data observed ${ }^{2}$ the upper critical temperature (UCTe) for moose in the summer was never exceeded during 'dark' hours. Conversely, only $13 \%$ of 'light' hours during the summer were beow the UCTe. Because the opportunity to sample moose locations during 'cool' and 'light' conditions was limited, only $3 \%$ of locations and $4 \%$ of activity samples were acquired under such conditions. This sample distribution precluded direct partitioning of the effects of heat and light on the cover selection and activity of moose.

Overall use of all CCC values did not differ from relative availability $(p>0.05)$. When locations were partitioned by temperature class, there was a significant difference in CCC use between Te $e_{o p e n}$ : hot and Teopen: cool conditions (Fig. 1, $p<$ 0.05). Total use of $\mathrm{CCC}=6$ stands was greater during 'hot' (thus 'light') conditions than during 'cool' (thus 'dark') conditions, (Fig. 1, $p<0.05$ ). Therefore, mose

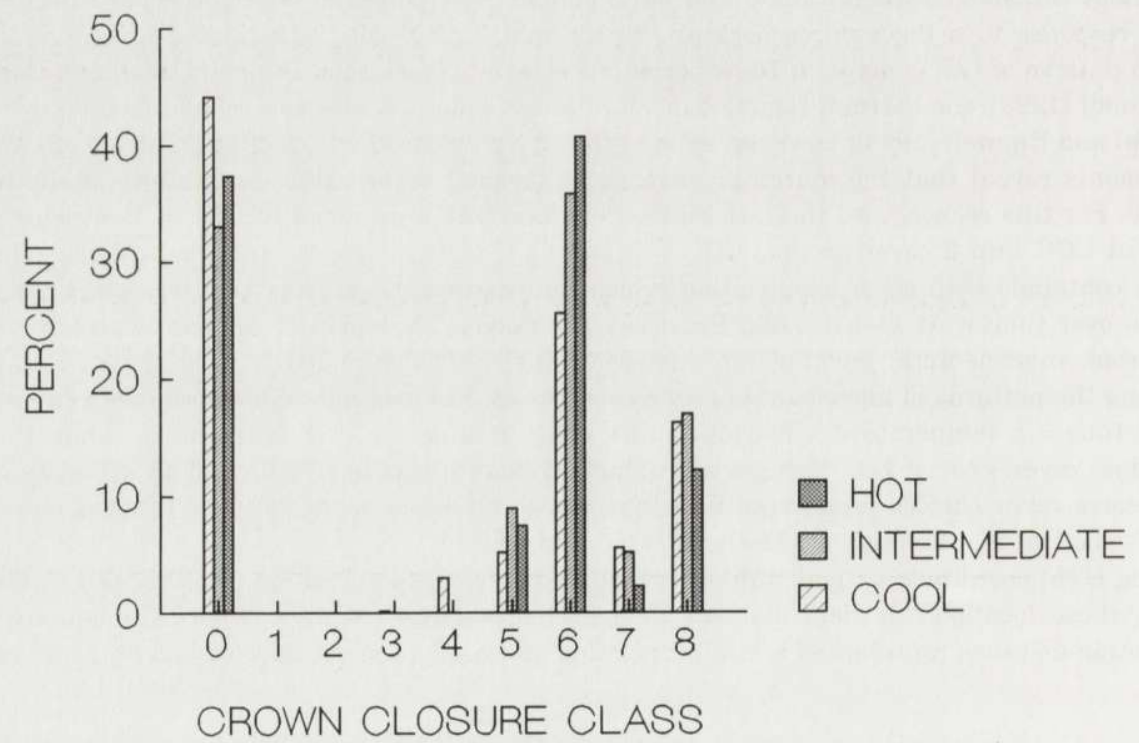

Fig. 1. Percentage of the area (ha) contained within moose telemetry overlays by crown closure class when Teopen was hot (daylight) $(n=124)$, intermediate $(n=72)$, and cool (darkness) $(n=56)$ in British Columbia during summer 1990.

${ }^{2}$ For a summary of weather data observed during the study period, refer to Demarchi and Bunnell 1993. 
generally used habitats in proportion to their availability, but modified use in response to temperature. No difference between total use of CCC $=0$ sites was detected between temperature classes (Fig. 1, $p>0.05$ ).

All summer forage plants of moose in the vicinity of the study area (Singleton 1976, Eastman and Ritcey 1987) are associated with riparian habitats (CCC $=0$ in this study). With the exception of edges and a few seepage sites, no forage species were found when moose locations in conifer stands were investigated on foot. Increased use of CCC $=6$ stands during 'hot' conditions apparently reflected use of those areas for the thermal cover they provided, not food.

If $\mathrm{CCC}=0$ sites provided no thermal cover, the similar use of $\mathrm{CCC}=0$ and CCC $=6$ on Te open: hot days (Fig. 1) implies that thermal cover was not being selected. Demarchi and Bunnell (1993) found that sites supporting dense willow stands $>5 \mathrm{~m}$ tall lacked a CCC designation on forest cover maps (CCC assumed 0 ) but intercepted an amount of solar radiation comparable to that intercepted by conifer stands of $\mathrm{CCC}=6$. Habitat polygons designated as $\mathrm{CCC}=0$ were usually associated with water. The apparent use of water by moose as a heat-sink has been reported (Ackerman 1987, Renecker 1987). Because water's potential to act as a heat-sink and the shade properties of willow trees were not factored into the operative temperature model, it can not be concluded that moose using areas of $\mathrm{CCC}=0$ were necessarily heat stressed when $\mathrm{Te}$ open exceed $29.5^{\circ} \mathrm{C}$. Indeed, the use of some $\mathrm{CCC}=0$ sites may have served to mitigate heat stress.

\section{Effects of thermal inertia}

For large animals such as moose, a small ratio of surface area to body volume results in reduced rates of heat transfer (Peters 1983). For example, slowed heat gain could mean that thermal cover is required only after sustained exposure to a hot environment. Fig. 2 shows how Te open values were distributed for moose locations from 11.00 until (but not including) 24.00. A significant increase in relative use of $\mathrm{CCC}=0$ sites $\left(p<0.05 ; 11.00\right.$ until $24.00, r^{2}=0.63 ; p<0.05 ; 11.00$ until $21.00, r^{2}=0.46$ ) corresponded to a significant decrease in Te $\mathrm{epen}_{\text {values for }}$

Fig. 2. Boxplot summary of hourly $\mathrm{Te}_{\text {open }}$ values when moose were located in British Columbia during summer 1990 for the hours of 11.00 until $24.00(n=243)$. Each boxplot shows the median and the range of the quartiles. Star and circle points are identified by SYSTAT (Wilkinson 1990) as outliers. The lines correspond to the UCT (dashed) and the thermal limit for open-mouthed panting (solid) identified by Renecker and Hudson (1986).

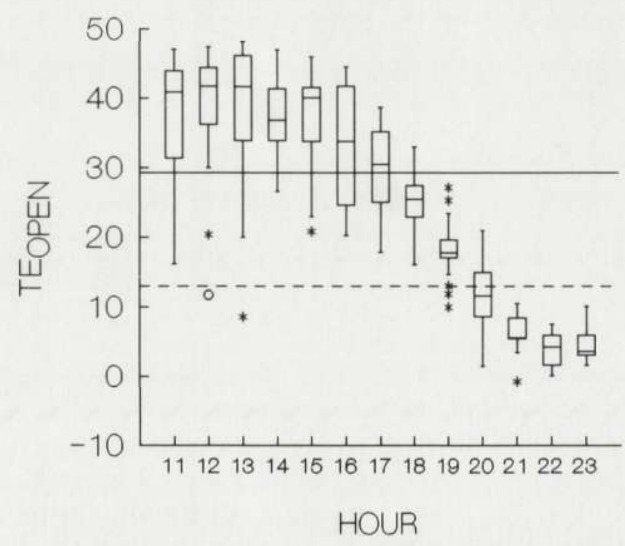






Fig. 3. Percentage of moose telemetry overlay areas in Crown Closure Class (CCC) $=0$ and CCC $\geq 4$ in British Columbia during summer 1990 for the period from 11.00 until $24.00(n=243)$. The relation between the ratio of $\mathrm{CCC}=0$ to $\mathrm{CCC} \geq 4$ overlay areas and hour is significant $\left(r^{2}=0.63, p<0.05\right)$.

the same period ( $p<0.05, r^{2}=0.75$ ) (Figs 2 and 3). Effects of light should be constant over the period of 11.00 until 21.00 (i.e. there are only light hours). The hour when the highest Teopen values were observed (13.00) was the hour when the ratio of $\mathrm{CCC}=0$ to $\mathrm{CCC} \geq 4$ overlay areas was smallest (Figs 2 and 3). Because not all sites of $\mathrm{CCC}=0$ had willow canopies capable of providing thermal cover, use of some forage-rich $\mathrm{CCC}=0$ sites appeared to be constrained by the thermal environment there. Because an increase in relative use of CCC $=0$ sites corresponded to a decrease in Teopen (even though 'light' conditions prevailed until



Fig. 4. Percentage of successive radio locations (i.e. $<120$ minutes apart) represented by cover type at time $=t$ and cover type at time $=t+1$ when Te $\mathrm{open}_{\text {was }}$ hot $(n=83)$, intermediate $(n=32)$, and cool $(n=37)$ for moose in British Columbia during summer 1990. Cover to cover (C-C), cover to open (C-O), open to cover $(\mathrm{O}-\mathrm{C})$, open to open $(\mathrm{O}-\mathrm{O})$. 
21.00 for most of the summer), thermal constraints appear to explain habitat selection. M. Demarchi (unpubl.) also found that use of CCC $=0$ sites by moose was least when the potential for thermal stress was greatest.

When temperature-specific patterns of cover selection were compared, moose under cover were more likely to remain under cover when Te $\mathrm{e}_{\text {open }}$ was 'hot' and 'intermediate' (Fig. 4, $p<0.05$ ). In addition, the least common pattern of cover selection under Teopen: hot conditions was 'cover to open'; providing further evidence that habitat selection was thermally constrained.

\section{Moose activity}

Moose activity was sampled $(n=326)$ over a range of ambient light and temperature conditions. Moose activity levels were dependent on temperature class $\left(\chi^{2}=7.448, \mathrm{df}=2, p<0.05\right)$. Inspection of Fig. 5 indicates that this difference was likely the result of the higher proportion of 'active' samples and/or the lower proportion of 'inactive' samples during Teopen: cool (thus 'dark') conditions compared to Teopen: intermediate and $\mathrm{Te}_{\mathrm{open}}$ : hot conditions. The similarity between activity levels during intermediate and hot conditions suggests the onset of heat stress was occurring closer to the lower limit of UCTam $\left(14^{\circ} \mathrm{C}\right)$ given by Renecker and Hudson (1986).

Cervid activity patterns can be temporally modified to avoid predators and other disturbances (Putman 1988). If predator activity is correlated with light conditions and moose attempt to avoid predators (e.g. to protect calves), temporal differences in moose behaviour could reflect predator avoidance. The estimated annual mortality rate for adult cow moose in the vicinity of the study area is extremely low (3.2\%), while for calves it is high (49\%) (Keystone Bio-Research, unpubl.). Although natural predation on moose calves in the study area has not been intensively researched, potential predators occurring there include: black

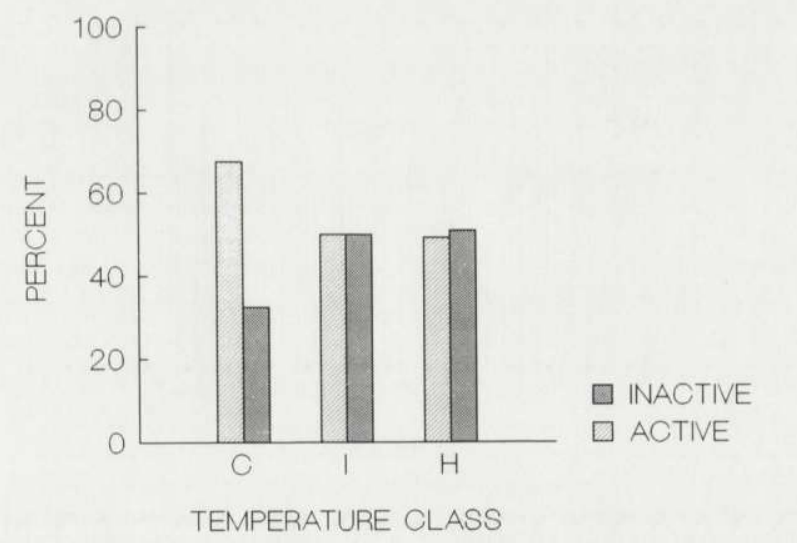

Fig. 5. Percentage of active and inactive moose radio locations under $\mathrm{Te}_{\text {open }}$ : cool $(\mathrm{C})(n=77), \mathrm{Te}_{\text {open }}$ : intermediate (I) $(n=94)$, and Te $e_{\text {open }}$ : hot $(\mathrm{H})(n=155)$ conditions in British Columbia during summer 1990. 
bear Ursus americanus and cougar Felis concolor. Amstrup and Beecham (1976) reported that in summer, black bear activity peaks were crepuscular and diurnal; van Dyke et al. (1986) reported that cougars were most active at night. Assuming risks of predation by black bear and cougar are equal, the temporal segregation of these predators implies that moose habitat selection or activity was not constrained by predators.

Using radio telemetry, Risenhoover (1986) concluded that variations in activity levels of moose were attributable to linear travel. Distance traveled or activity levels of moose in summer have been reported to be greatest at night (Phillips et al. 1973, Joyal and Scherrer 1978), at night and early in the morning (van Ballenberghe and Miquelle 1990), and around dawn and dusk (Belovsky and Jordan 1978). Van Ballenberghe and Miquelle (1990) noted that shorter activity bouts "appeared" to be associated with warmer temperatures at midday; their data, however, were not tested. De Vos (1958) noted that although moose were not as readily observed at midday compared to morning and evening, they "seemed" to be observed more on hot compared to cool afternoons. Despite this trend, de Vos (1958) was unable to demonstrate a correlation between air temperature and moose observability. Joyal and Scherrer (1978) reported that moose "seemed" more active on clear (thus, likely warmer) summer days but that no significant differences between the movements on clear, cloudy, or rainy days were detected. Ackerman (1987) found that as black globe temperature increased, forage-bout duration decreased significantly and bedded duration increased significantly; in both instances, the reported $r^{2}$ value was less than 0.40 . We believe that because data used by Ackerman in those analyses were weekly averages of the independent and dependent variables, his results are inconclusive.

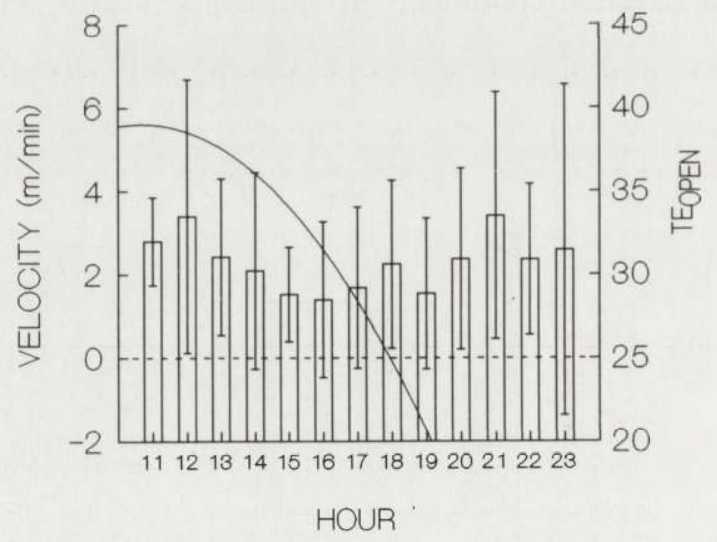

Fig. 6. Average 'mean straight line velocity' ( $\pm 1 \mathrm{SD}$ ) between successive moose locations from 11.00 until 24.00 during summer 1990 in British Columbia $(n=209)$. The curved line represents the non-linear least square regression of operative temperature in open areas against hour for times when moose were located $\left(n=242, r^{2}=0.75, p<0.05\right)$. 
In short, published evidence conclusively demonstrating a strong effect of heat on the activity levels of moose is lacking. In this study, mean interlocation straight-line velocity (MSLV) was not correlated with Te $\mathrm{Tepen}_{(}(r=-0.06, n=205)$ or hour $(r=0.03, n=205)$; from Fig. 6 , however, a trend of decreasing velocity existed from 12.00 until 17.00. The curved line in Fig. 6 demonstrates how Teopen changed across those hours when velocity was estimated. The trend in decreasing velocity as the duration of exposure to $\mathrm{Te}_{\text {open }}>29.5^{\circ} \mathrm{C}$ increased supports the hypothesis that moose decrease travel distance (thereby potentially decreasing activity) with increasing ambient heat load. An analysis of variance conducted on the hourly mean velocities from 12.00 until 18.00 indicated a significant difference between hourly means at $\alpha=0.10$. Testing the means (Tukey's HSD test) revealed that the significant result was due to the difference between values at 12.00 and 16.00 .

The effect of the thermal environment on moose activity was analyzed in the context of Teopen. Therefore, use of stands providing thermal cover may have allowed for increased activity when activity was thermally constrained on CCC = 0 sites (i.e. although it may be hot in the open, at the same time it can be cool under cover). If this was true, the proportion of active locations for 'cool' conditions would increase further. A negative correlation between percent of active locations and mean hourly Te $\mathrm{Tepen}(r=-0.47, p<0.05, n=13)$ indicated a trend of decreasing

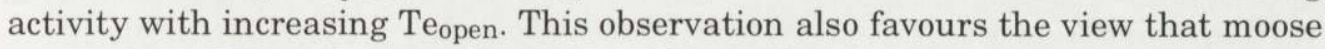
were responding to heat and not to predators, because for most of the summer, 'light' conditions existed until 21.00.

\section{Management implications}

Moose are very susceptible to thermal stress (Renecker and Hudson 1986). The influence of forest canopies on the thermal environments below them (Demarchi and Bunnell 1993), and the patterns of cover selection and activity found in this study indicate that cow moose respond to thermal stress by using thermal cover and reducing activity.

Research on moose bioenergetics suggests that moose require summer thermal cover regardless of forage abundance (e.g. Renecker 1987). The results of this study indicate that moose select summer thermal cover and that this cover can be quantified from simple management indices such as forest cover maps (Demarchi and Bunnell 1993). The primary management implication is that for moose in this area, managing summer thermal cover at the level of forest cover polygons appears warranted.

Acknowledgments: This is publication R-12 of the Centre for Applied Conservation Biology. The authors thank Environment Canada and the British Columbia Ministries of Forests and Environment for providing technical materials. K. Simpson provided logistical support. J. Chen, T. Black, J. Maedel, and P. Murtha provided technical support. The project was funded by: National Science and Engineering Research Council through a grant to F. Bunnell, British Columbia Ministry of Forests, Gorman Brothers Lumber, Ardew Wood Products, Fletcher Challenge Canada, and Weyerhaeuser Canada. J. Johnson and B. Moody coordinated funding. 


\section{References}

Ackerman T. N. 1987. Moose response to summer heat on Isle Royale. M. Sc. thesis, Michigan Technological Univ., Houghton, Michigan: 1-53.

Amstrup S. C. and Beecham J. 1976. Activity patterns of radio-collared black bears in Idaho. Journal of Wildlife Management 40: 340-348.

Ballenberghe V. van and Miquelle D. G. 1990. Activity of moose during spring and summer in interior Alaska. Journal of Wildlife Management 54: 391-396.

Belovsky G. E. and Jordan P. A. 1978. The time-energy budget of a moose. Theoretical Population Biology 14: 76-104.

Black H., Scherzinger R. and Thomas J. W. 1976. Relationships of Rocky Mountain elk and Rocky Mountain mule deer habitat to timber management in the Blue Mountains of Oregon and Washington. [In: Proceedings of the elk-logging-roads symposium. S. R. Heib, ed]. University of Idaho, Moscow, Idaho: 11-31.

Black T. A., Chen J. M., Lee X. and Sagar R. M. 1991. Characteristics of shortwave and longwave irradiances under a Douglas-fir forest stand. Canadian Journal of Forestry Research 21: 1020-1028.

Bligh J. and Johnson K. G. 1973. Glossary of terms for thermal physiology. Journal of Applied Physiology 35: 941-961.

Bunnell F. L. and Gillingham M. P. 1985. Foraging behavior: the dynamics of dining out. [In: Bioenergetics of wild herbivores. R. J. Hudson and R. G. White, eds]. CRC Press, Miami, Florida: 53-79.

Bunnell F. L., Parker K. L., Kremsater L. L. and Hovey F. W. 1987. Thermoregulation and thermal cover of deer and elk on Vancouver Island: problem analysis. British Columbia Ministry of Forests, WHR-23: 1-96.

Campbell G. S. 1977. An introduction to environmental biophysics. Springer, New York: 1-159.

Chen J. M., Black T. A. and Adams R. S. 1991. Evaluation of hemispherical photography for determining plant area index and geometry of a forest stand. Agricultural and Forest Meteorology 56: $129-143$.

Dealy J. E. 1985. Tree basal area as an index of thermal cover for elk. United States Department of Agriculture, Forest Service, Pacific Northwest Forest and Range Experiment Station. Research Note PNW-425: 1-6.

Demarchi D. A. 1990. The environment. [In: The birds of British Columbia, volume one. W. R. Campbell, senior ed]. Royal British Columbia Museum, Victoria, British Columbia: 55-146.

Demarchi M. W. and Bunnell F. L. 1993. Estimating forest canopy effects on summer thermal cover for Cervidae (deer family). Canadian Journal of Forestry Research 23: 2419-2426.

Dyke F. G. van, Brocke R. H., Shaw H. G., Ackerman B. B., Hemcker T. P. and Lindzey F. G. 1986. Reactions of mountain lions to logging and human activity. Journal of Wildlife Management 50: 95-102.

Eastman D. S. and Ritcey R. 1987. Moose habitat relationships and management in British Columbia. Swedish Wildlife Research Supplement 1: 101-117.

Hicks C. R. 1982. Fundamental concepts in the design of experiments. Holt, Rinehart, and Winston, New York: 1-425.

Joyal R. and Scherrer B. 1978. Summer movements and feeding by moose in western Quebec. Canadian Field-Naturalist 92: 252-258.

Kremsater L. L. and Bunnell F. L. 1992. Testing responses to forest edges: the example of black-tailed deer. Canadian Journal of Zoology 70: 2426-2435.

Leckenby D. A. and Adams A. W. 1981. Eastern Oregon cover study interim report. Oregon Department of Fish and Wildlife, Research and Development Section, Information Report Series, Wildlife 81-1: 1-68. 
Lloyd D., Angrove K., Hope G. and Thompson C. 1990. A guide to site identification and interpretation for the Kamloops Forest Region. British Columbia Ministry of Forests, Land Management Handbook No. 23: 1-398.

Lyon L. J. 1979. Influences of logging and weather on elk distribution in western Montana. United States Department of Agriculture, Forest Service, Intermountain Forest and Range Experiment Station, Research Paper INT-236: 1-11.

Mautz W. W. 1978. Nutrition and carrying capacity. [In: Big game of North America: Ecology and management. J. L. Schmidt and D. L. Gilbert, eds]. Stackpole Books, Harrisburg, Pennsylvania: 321-348.

Merrill E. H. 1991. Thermal constraints on use of cover types and activity time of elk. Behavioural Sciences 29: 251-267.

Norman J. M. and Campbell G. S. 1989. Canopy structure. [In: Plant physiological ecology: field methods and instrumentation. R. W. Pearcy, J. Ehlinger, H. A. Mooney, and P. W. Rundel, eds]. Chapman and Hall, New York: 300-325.

Nyberg J. B. and Janz D. W. 1990. Deer and elk habitats in coastal forests of southern British Columbia: a handbook for forest and wildlife managers. British Columbia Ministries of Forests and Environment, Victoria, British Columbia: 1-310.

Parker K. L. and Gillingham M. P. 1990. Estimates of critical environments for mule deer. Journal of Range Management 43: 73-81.

Pederson R. J. 1975. Pre-logging elk habitat use. [In: Proceedings of the elk-logging-roads symposium. S. R. Heib, ed]. University of Idaho, Moscow, Idaho: 85-87.

Pederson R. J., Adams A. W. and Skovlin J. M. 1980. Elk habitat in an unlogged and logged forest environment. Oregon Deptartment of Fish and Wildlife, Wildlife Resarch Report 9: 1-121.

Peek J. M., Scott M. D., Nelson L. J., Pierce D. J and Irwin L. L. 1982. Role of cover in habitat management for big game in northwestern United States. Transactions of the North American Wildlife Conference 47: 363-373.

Peters R. H. 1983. The ecological implications of body size. Cambridge Univ. Press, New York: 1-329.

Phillips R. L. Berg W. E. and Siniff D. B. 1973. Moose movement patterns and range use in Northwestern Minnesota. Journal of Wildlife Management 37: 266-278.

Putman R. 1988. The natural history of deer. Comstock Publishing Associates, Ithaca, New York: $1-191$.

Renecker L. A. 1987. Bioenergetics and behaviour of moose (Alces alces) in the aspen-dominated boreal forest. Ph. D. thesis, University of Alberta, Edmonton: 1-265.

Renecker L. A. and Hudson R. J. 1986. Seasonal energy expenditures and thermoregulatory responses of moose. Canadian Journal of Zoology 64: 322-327.

Risenhoover K. L. 1986. Winter activity patterns of moose in interior Alaska. Journal of Wildlife Management 50: 727-734.

Ritcey R., Lowe D., Harestad A., Campbell R. W. and Harcombe A. P. 1988. Species habitat relationship models for mammals. Vol 5. [In: Wildlife habitat handbooks for the Southern Interior Ecoprovince. A. P. Harcombe, ed]. British Columbia Ministries of Environment and Forests, Victoria: 1-252.

Schwab F. E. 1986. Moose habitat selection in relation to forest cutting practices in northcentral British Columbia. Ph. D. thesis, University of British Columbia, Vancouver: 1-176.

Singleton J. M. 1976. Food habits of wild ungulates in British Columbia: Bibliography and plant synopsis. British Columbia Fish and Wildlife Branch, Victoria: 1-51.

Springer J. T. 1979. Some sources of bias and sampling error in radio triangulation. Journal of Wildlife Management 43: 926-935.

Thomas J. W., Black J., Jr, Scherzinger R. J. and Pedersen R. J. 1979. Deer and elk. [In: Wildlife habitats in managed forests: the Blue Mountains of Oregon and Washington. J. W. Thomas, ed]. United States Government Printing Office, Washington: 104-127. 
Vales D. J. and Bunnell F. L. 1988. Relationships between transmission of solar radiation and coniferous forest stand characteristics. Agricultural and Forest Meteorology 43: 201-223.

Vos A. de 1958. Summer observations on moose behaviour in Ontario. Journal of Mammalogy 39: 128-139.

Wilkinson L. 1990. SYSTAT: the system for statistics. Systat Inc., Evanston, Illinois: 1-677.

Young V. A. and Robinette W. L. 1939. A study of the range habits of elk on the Selway Game Preserve. University of Idaho Bulletin No. 16, Moscow: 1-47.

Zar J. H. 1984. Biostatistical analysis. Second edition. Prentice-Hall, Inc., Englewood Cliffs, New Jersey: 1-718.

Received 21 March 1994, accepted 27 November 1994. 